\title{
Current Situation of Drug Abuse and Countermeasures in Japan
}

\author{
Shinji Nakamura ${ }^{a}$
}

\begin{abstract}
Drug abuse is a common problem that all countries in the world face. The most distinguishing characteristic of drug abuse in Japan is that use of stimulants, mostly methamphetamine, accounts for over $80 \%$ of the arrests. Abuse of a stimulant called Philopon was widespread after the Second World War in Japan, but the situation was dramatically improved after 1954 because the Japanese government enacted the Stimulant Control Act and restructured the police system and Japanese society recovered from post-war unrest. The situation of drug abuse in Japan has become less serious compared to the past and to the situation in many other countries, because we are taking comprehensive and nationwide measures, including proactive disclosure of the situation, control, drug abuse prevention class, and introduction of partial suspension of sentence. On the other hand, as in many countries, the rapid spread of new psychoactive substances (NPS) in recent years became a serious social issue. The situation of NPS has been rapidly improving due to comprehensive and government-wide measures, but the means of acquisition is quickly shifting to the Internet. It is necessary to strengthen cyber patrol.
\end{abstract}

\section{Keywords}

Comprehensive and nationwide measures, new psychoactive substances, cyber patrol

The gravity of the situation may vary by country, but drug abuse is a common problem that all countries in the world face, and each country has implemented various countermeasures in collaboration with other countries worldwide. Major anti-drug measures are divided into two types. One type is on the demand side, which includes strengthening drug abuse control through criminal investigations and trials, provision of assistance such as counseling and treatment to drug abusers, provision of drug abuse prevention class at schools and other institutions, and raising public awareness extensively among citizens. The other type is on the supply side, which includes interdiction of the entry of illicit drugs into Japan at the borders through international collaboration, thorough crackdown on trafficking syndicates, and dissolution of criminal syndicates. Each country has implemented anti-drug measures applying a variety of methods comprehensively, but the current state of affairs is that no country has established decisively effective measures.

With this in mind, this document outlines the current situation of drug abuse and countermeasures in Japan. The current situation of drug abuse in Japan is not overly serious compared to various other countries in the world. However, noting that abuse of stimulants was once spread widely, immediately following the Second World War, and that new psychoactive substances (NPS) have been rapidly spreading in

\footnotetext{
aNational Police Academy, Tokyo, Japan

Correspondent Author:

Shinji Nakamura, 3-12-1 Asahi-Cho Fuchu City, Tokyo, Japan
} 
recent years, the government of Japan has thoroughly implemented comprehensive anti-drug measures with the domestic and international cooperation of relevant institutions. The author hopes that the current situation of drug abuse and countermeasures in Japan presented in this document will be a good reference for anti-drug measures in many other countries and will also contribute to studies by researchers on drug abuse.

Further, the author would like to state in advance that the views that he mentions in this document are himself personally and are not the official views of the Japanese government, although the author is a member of the National Police Agency.

\section{CURRENT SITUATION OF DRUG ABUSE AND COUNTERMEASURES IN JAPAN}

This paper consists of two major parts. The first part is on the current situation of drug offences and anti-drug measures in Japan. The second part is on the current situation of NPS, which have recently become a serious social issue in Japan, and measures against them. The author will outline them later in this document.

To explain the current situation of drug offences in Japan, the author would like to point out Figure 1 below, which is international comparison of the situations in different countries. The lifetime prevalence of illicit drugs in Japan is at only $2.9 \%$, which is significantly lower than the rates in other countries, which are $47.1 \%$ in the United States, 45.2\% in Canada, 36.8\% in the United Kingdom, and $23.7 \%$ in Germany ${ }^{1}$.

Some may point out that drug abuse is not as serious in Japan as in other countries because the penalties against them are severe in Japan, and the investigating authority exercises strict control. However, anti-drug measures are not so simple that implementation of strict penalties alone will lead to improvement of the situation. Many drug abusers are addicted to drugs and in conditions where they cannot live without them; so they do not make decisions on whether to use drugs or not only based on the existence or nonexistence of penalties. Many drug abusers are rather in conditions where they cannot control their own usage of drugs.

Therefore, when implementing anti-drug measures, it is important to include all types of measures, instead of relying only on control of illicit drugs. In Japan, from this viewpoint, the relevant government ministries and agencies have formulated government-wide and comprehensive anti-drug measures, while proactively disclosing information to citizens. Furthermore, in collaboration with entities such as volunteer groups, the government has implemented various types of government-wide anti-drug measures, including public awareness-raising among all citizens and drug abuse prevention class at schools. These efforts have resulted in the low rate in Japan for lifetime prevalence of illicit drugs.

Next, see Figure 2, regarding persons arrested for drug-related crimes in 2015. The most distinctive characteristic of drug abuse in Japan is that use of stimulants, mostly methamphetamine, accounts for over $80 \%$ of the arrests. The rates of arrests by use of stimulants have been over $80 \%$ for the past six years. The rate by use of cannabis follows stimulants, at 15.5\%, MDMA (methylene dioxymetham-phetamine) including Ecstasy at $0.3 \%$, cocaine at $0.6 \%$, and the others at $2.1 \%$. When anti-drug measures are considered in Japan, this means that most of the measures are against the use of stimulants. However, in recent years, in addition to the spread of cannabis among young people, the rapid spread of NPS has become a serious social issue, which the author will describe later.

Next, see Figure 3, on medium- to long-term trends of drug abuse in Japan since 1945, the year that World War II ended in Japan, Japan has seen three peak periods of drug abuse. 


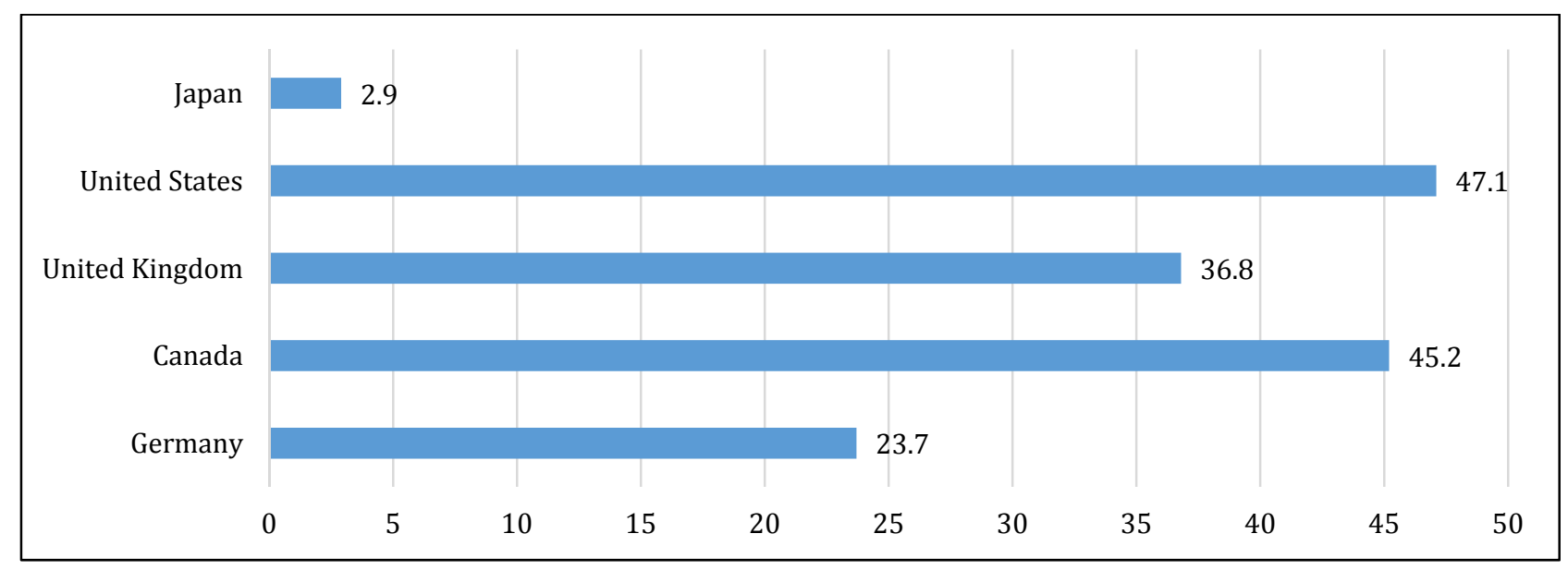

Figure 1. Lifetime Prevalence of Illicit Drugs by Country.

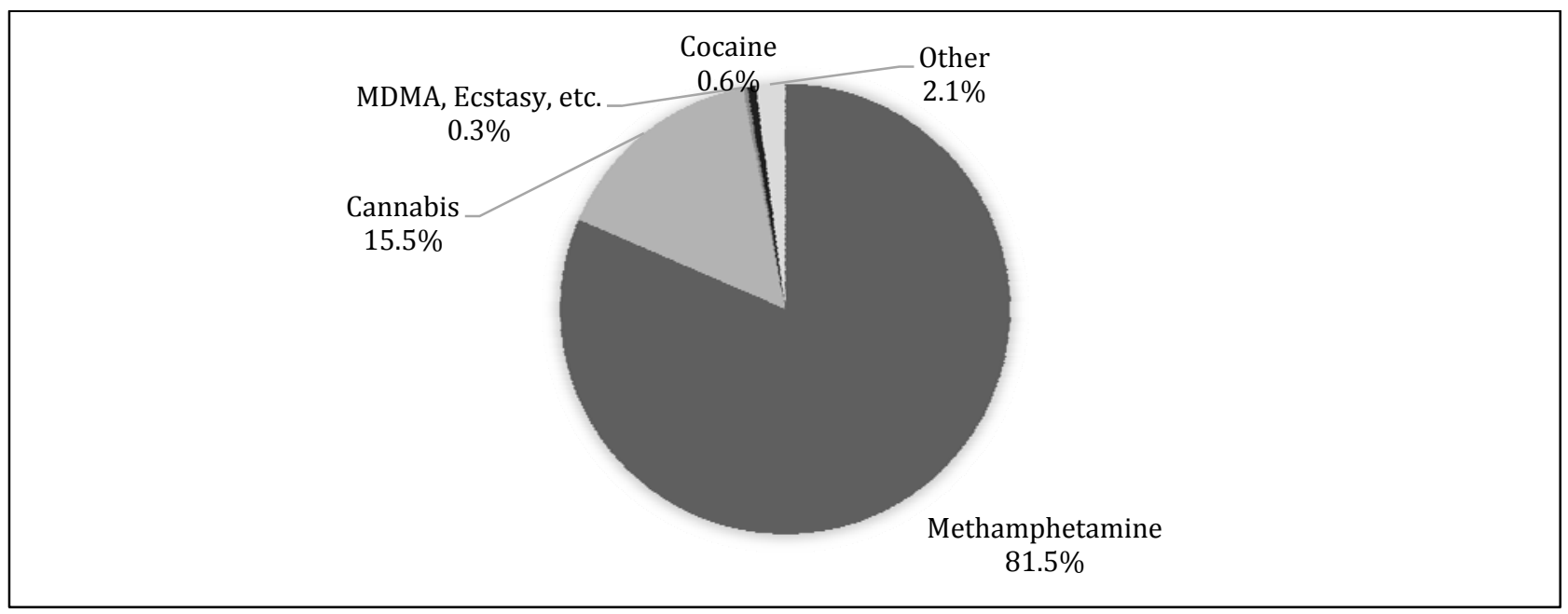

Figure 2. Percentage of Persons Arrested for Drug-Related Crimes, 2015.

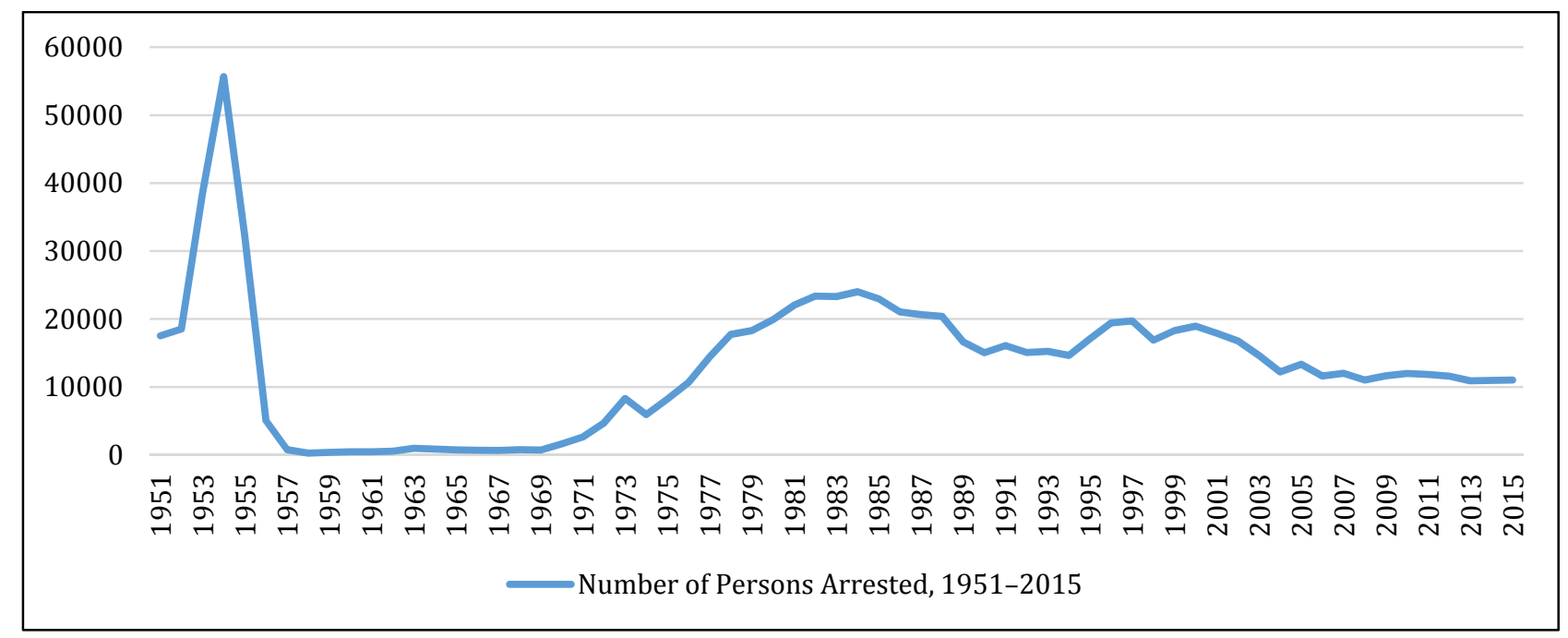

Figure 3. Number of Persons Arrested, 1951-2015. 
The first abuse period was around 1953, right after the end of the Second World War. In this period in Japan, a stimulant called Philopon was widespread. It was a period of poor public security following the war, caused by deterioration of the nation and peoples' lives, and many people abused the stimulant, partly because the country had not established a police system that could sufficiently maintain public order. In these circumstances, the government enacted the Stimulant Control Act in 1951 to enhance control over stimulants. The number of persons arrested annually continued to increase over the following several years, and over 55,000 persons were arrested in 1954. The situation improved after 1954, as Japanese society recovered from post-war unrest, and through measures taken by relevant agencies, including control by the police, the number of persons arrested was reduced to less than 1,000 in 1957 and subsequent years.

After World War II, the police organization was dissolved and changed from the prewar national and prefectural police structure to a municipal structure where all municipalities, including cities and towns, had police forces. This resulted in rivalry between jurisdictional police and inefficient organizational management as a whole. This, combined with post-war unrest, significantly weakened the capacity of the police to maintain public security, which possibly influenced the deterioration of the drug abuse situation. To overcome shortcomings of this structure, the government enacted the current Police Act in 1954, in which the basic control of police administration, including investigations, was under prefectural governments, which mitigated the issues of rivalry between jurisdictional police and inefficient organizational management.

The second abuse period peaked in 1984. The number of persons arrested started increasing from around 1970, and reached approximately 24,000 in
1984, which was a peak year. The background of the increase was that Japanese criminal syndicates, namely Boryokudan, involved themselves in smuggling and trafficking of stimulants as new income sources. They were recognized to be controlling trafficking of stimulants in Japan, and the Japanese police strengthened its crackdown on Boryokudan to eradicate them and improve the situation. Ever since, we have seen certain effects of this crackdown, and the number of persons arrested for crimes relating to stimulants has gradually decreased. However, the Boryokudan still control trafficking of stimulants in Japan today. In 2015, the Japanese police arrested 542 persons for drug trafficking, among whom 358 belonged to the Boryokudan, accounting for $66 \%$ of the total number.

The third abuse period peaked around 1997. The situation gradually improved after the second abuse period, but the numbers started to increase in 1995 and reached approximately 20,000 in 1997. In the third abuse period, drug abuse by young people became noticeable, accounting for approximately half of the total numbers. More than half of the individuals arrested were first offenders. This indicates that drug abuse has spread from limited abusers to wider groups, including young people. Due to the promotion of comprehensive anti-drug measures as mentioned later, the number has gradually decreased ever since, and the number is approximately 10,000 today.

\section{Promotion of Government-Wide and Comprehensive Anti-drug Measures}

As described above, Japan faced a third drug abuse period with its peak in 1997. To respond to this situation, the Japanese government formulated the Five-Year Drug Abuse Prevention Strategy in 1998, to have relevant ministries and agencies closely collaborate, and to promote comprehensive 
nationwide measures against drug abuse, while proactively communicating the ongoing situation to citizens and collaborating with other relevant entities such as volunteer groups and private organizations. This strategy has been renewed every five years since, and various measures are in progress today in accordance with the Fourth Five-Year Drug Abuse Prevention Strategy that was formulated in 2013.

The Fourth Five-Year Drug Abuse Prevention Strategy has established five objectives: (1) to prevent people from abusing drugs by enhancing efforts to raise awareness among young people, families, and communities and by boosting normative consciousness; (2) to strictly prevent relapse into drug abuse by supporting drug abusers through treatment and reintegration into society and by enriching support for their families; (3) to eliminate illicit drug trafficking organizations, exercise thorough control over endusers, and strengthen oversight of diversifying drugs for abuse; (4) to interdict entry of illicit drugs into Japan through a strict crackdown at the border; and (5) to promote international cooperation to interdict drug smuggling.

We may regard promotion of controlling illicit drugs and provision of treatment and counseling to drug abusers as major preventive measures against drug abuse, but there is no single measure that is decisively effective, and it is important to implement comprehensive measures on both the supply side and the demand side.

To introduce some of the measures that have been implemented in Japan and may be useful for other countries, one example is drug abuse prevention classes that are conducted by relevant lecturers, including police officers, at various schools, but mainly at elementary, junior high, and high schools. The objectives of the classes are to boost normative consciousness and to create a social movement toward elimination of drug abuse. Police officers who give lectures based on actual drug abuse cases are especially persuasive for students (see Figures 4 and 5).

To promote control of illicit drugs, we use wire tapping and strengthen control of organized smuggling and trafficking. In addition to the police, there are narcotics control offices under the Ministry of Health, Labour and Welfare of Japan. Exercising investigations by multiple agencies in a competitive manner is leading to more effective control. Meanwhile, organizations concerned, including the police, customs, the Immigration Bureau, the Ministry of Health, Labour and Welfare, and the Japan Coast Guard, closely exchange information with each other to interdict entry of illicit drugs from overseas.

Furthermore, taking into account the current environment, where drugs are distributed globally, Japan has made efforts to uncover and eradicate smuggling routes through international collaboration and close information exchange with other countries.

\section{Measures to Prevent Relapse Into Drug Abuse}

As Aida (2015) explained, prisoners in Japan who serve time for illicit drug abuse receive guidance in prisons to prevent relapse into drug abuse after their prison terms. The guidance is designed to allow abusers to understand the problems and effects of drug usage, and to give thought to what they can do to prevent relapse into drug abuse when they leave prison. In 2014, there were 6,694 prisoners who received the guidance.

In addition, probationers undergo a specialized treatment program for those who have used stimulants voluntarily and have probation periods of six months or more. This program is based on expertise in psychology and other fields and is conducted to prevent relapse into drug abuse by applying methods such as cognitive behavioral therapy. The program also conducts tests for illicit drug for the purpose of maintaining and improving the incentive of drug abusers to recover. In 2014, there were 1,270 probationers who commenced participation in this program. 


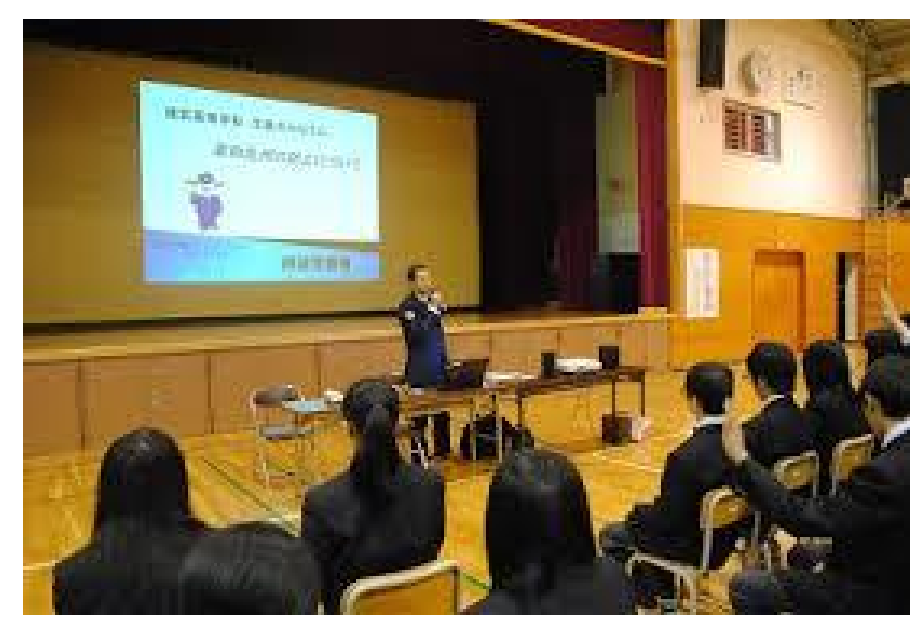

Figure 4. Drug Abuse Prevention Class by a Police Officer.

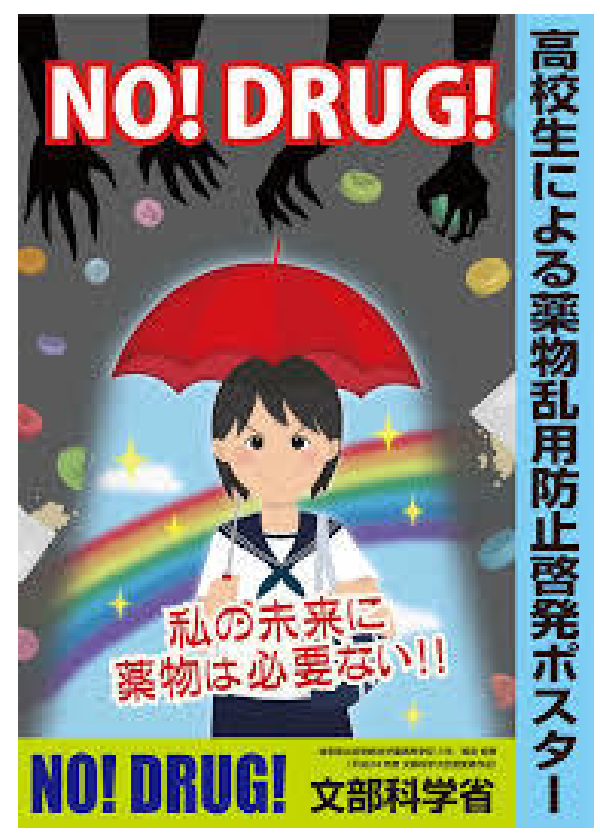

Figure 5. Educational Poster.

\section{Introduction of Partial Suspension of Execution of Sentence}

As Higashiyama (2013) explained, the government introduced partial suspension of execution of sentences in June 2016 to enhance treatment for drug abusers in society. Before the introduction of this system, a person sentenced to, for example, three years in prison literally spent three years in prison, without probation, except for cases where the person was released before serving the full sentence.

The introduction of this system allows the final year of the three-year sentence to be converted to three years of suspension of execution of the sentence, as an example, offering the person an opportunity to undergo rehabilitation in society in the probationary period (see Figure 6). 


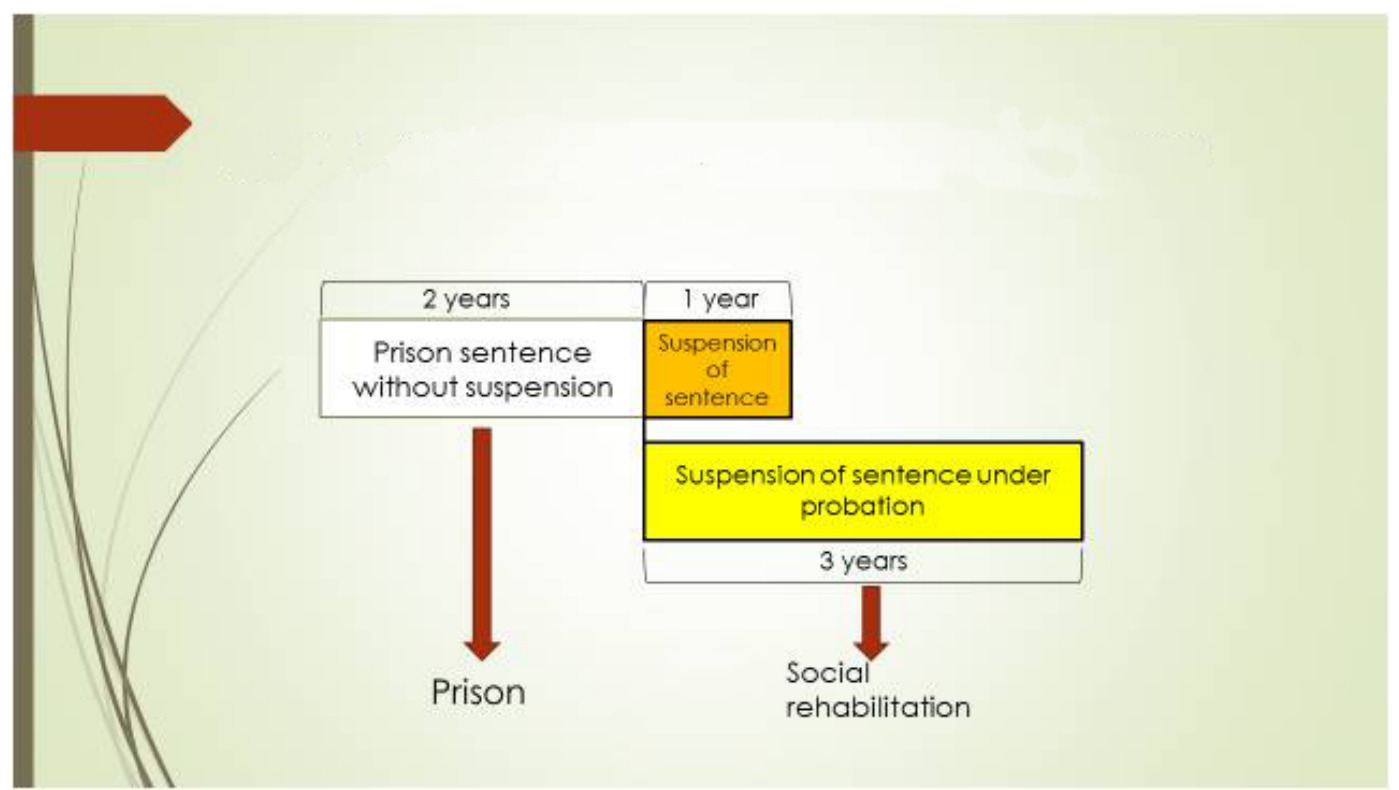

Figure 6. Partial Suspension of Execution of Sentence.

This system was introduced to add another choice to measures to prevent drug offenders from relapsing into drug abuse and to urge them to recover from drug abuse through rehabilitation in society under pressure of repeated imprisonment for repeat offences.

While use of drugs in prisons is not observed in Japan, as it is observed in some other countries, and repeated drug abuse during imprisonment is not a concern, over $60 \%$ of persons arrested for drug abuse are repeat offenders, which highlights prevention of repeat offences after imprisonment as a critical challenge. Many drug abusers cannot control their use of drugs by their own will.

While the former system allowed applying only the remaining sentence period for a probation period, even when a prisoner is conditionally released before serving the full sentence, the introduction of the new system has enabled provision of treatment to drug abusers for a longer period. The new system also offers more choices when considering which penalties to impose on defendants.

While prisoners who are subject to this system may leave prison with shorter periods of imprisonment, they take on the risk of repeated imprisonment if they repeat a drug offence. This system can be applied not only to first offenders but also to repeat offenders, and when partial suspension of execution of sentence is applied to drug offenders, it is always combined with probation.

\section{THE CURRENT SITUATION OF NEW PSYCHOACTIVE SUBSTANCES (NPS) AND MEASURES AGAINST THEM IN JAPAN}

\section{History of the Spread of NPS in Japan}

The second major topic is the current situation of NPS and measures against them in Japan. The rapid spread of NPS in recent years, as in many other countries, has become a serious social issue in Japan. In the first place, the emergence of substances that were not restricted but had similar effects as restricted substances became a social issue in 1990s.

What was mainly used then was magic mushrooms. The name became known around 1998, 
and there were cases where users were hospitalized or died. Around 2004, when the number of shops that sold NPS was increasing, there was a case where a user of NPS committed murder. Since then, use of NPS, which were called law-evading drugs (Dappo drugs) or legal herbs (Goho herbs) in Japan, has gradually spread.

\section{Measures Against NPS}

To respond to this situation, in 2006, the government introduced a control system for designated substances to exercise control over NPS. The system included banning the use of designated substances in addition to traditional drugs such as stimulants, which brought about certain positive effects.

On the other hand, substances with slightly different chemical structures from designated substances were produced and sold one after another to evade controls, suggesting that the regulatory method could not flexibly cope with reality. This lead to implementation of a generic scheduling system in 2012, which enabled collective control of substances with similar chemical structures. Under this system, 772 substances were designated and became subject to control in February 2013, followed by 504 substances in December 2013, and 840 substances in May 2015. Additionally, simple possession and simple use of designated substances became subject to control in April 2014.

In spite of a series of these enhanced measures, a man driving a car under the influence of NPS killed and injured eight pedestrians in Tokyo in June 2014, which brought large public interest in incidents and accidents caused by NPS. In these severe situations, the Japanese government established an emergency countermeasure to eliminate abuse of NPS in July of that year. This countermeasure focused on thorough communication of the current situation to raise awareness, rapid designation of substances to strengthen control over them, and flexible review of controls in accordance with current situations.

Meanwhile, with the viewpoint that the names used for NPS in Japan before the emergency countermeasure, namely law-evading drugs and legal herbs, were one of the factors that make people disregard risks and use these drugs without hesitation, the government decided to use a unified term, dangerous drugs (Kiken drugs) for these substances to raise awareness of the risks involved. Figure 7 shows the Chairman of the National Safety Commission announcing the new name. The Japanese characters shown in the image mean "dangerous drugs".

\section{Changes in the NPS Situation}

Reflecting the worsening NPS situation, the number of persons arrested for NPS use has increased. As shown in Figure 8, compared to only six persons arrested in 2011, the number rapidly increased to 1,196 in 2015. The particularly rapid increase since 2014 was due to a change to make simple possession and simple use of NPS subject to penalty in April of that year. It was also due to strengthening of control to respond to an increased public opinion requesting tighter control, which was influenced by cases such as an incident in which a driver under the influence of NPS killed and injured pedestrians. Superficially, the rapid increase in the number of arrestees may give the impression that the situation is rapidly worsening, but on the contrary, the NPS situation in Japan has been quickly improving, especially since 2015.

Until the generic scheduling system was implemented in 2012, which allowed collective designation of substances with similar chemical structures, new substances with effects similar to those of designated substances emerged one after another, which made effective control of NPS difficult. Implementation of the generic scheduling system enabled effective control, and an additional change in April 2014 to make simple possession and simple use of NPS subject to penalty, promptly promoted effective control by law enforcement authorities, leading to an increase in the number of persons being arrested. Although the number of arrestees continued 


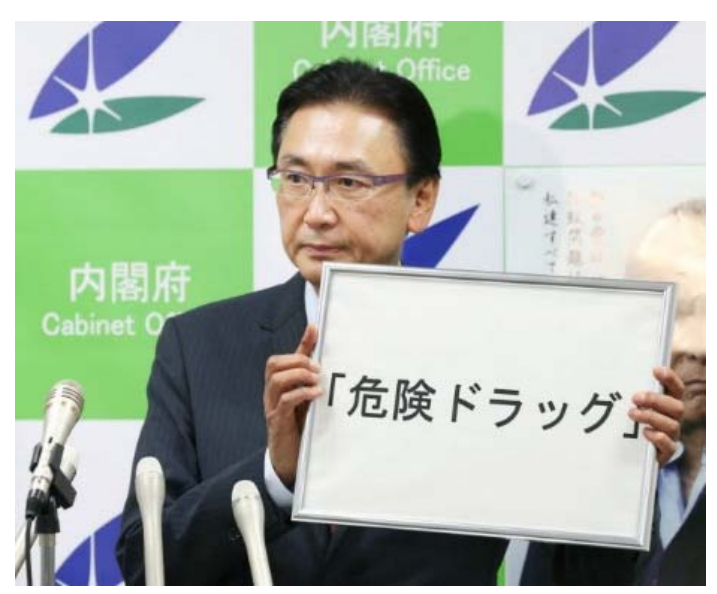

Figure 7. The New Name Being Announced.

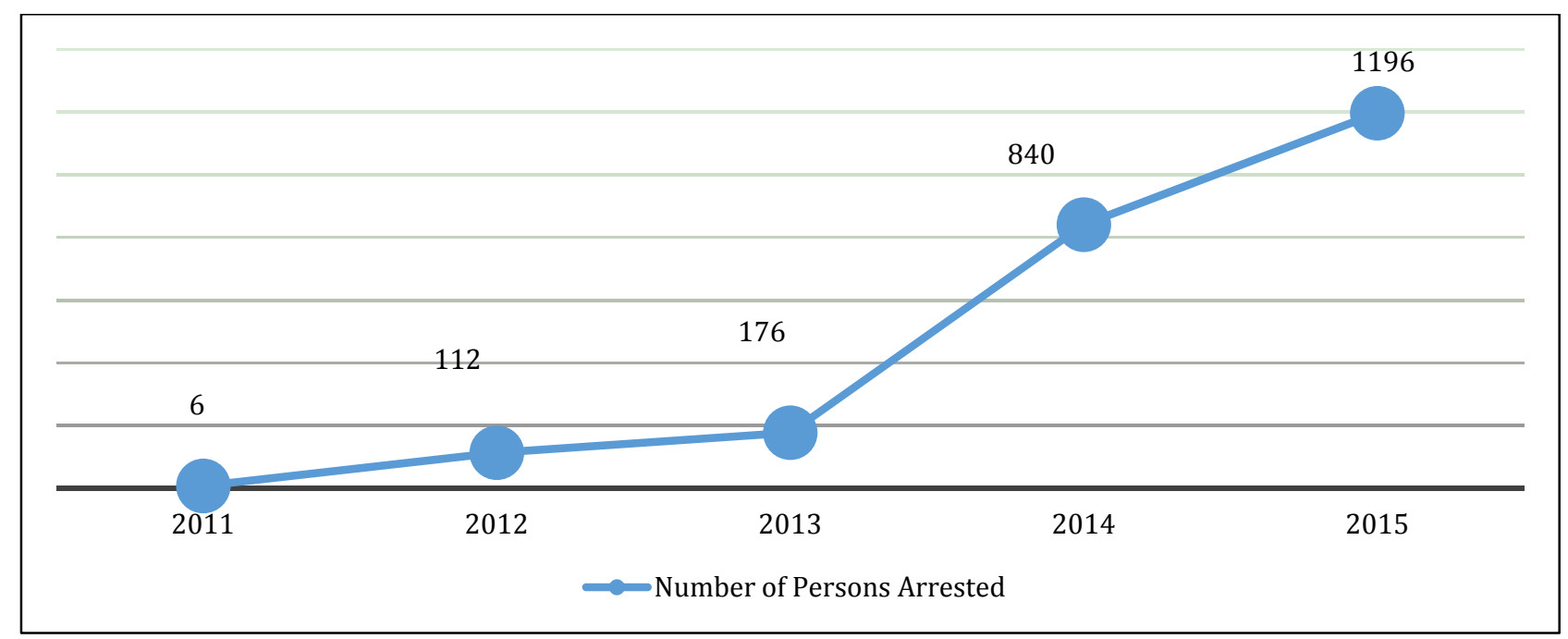

Figure 8. NPS: Number of Persons Arrested.

to increase in 2015, more than half of them were those who had been recognized by 2014, and the monthly number of recognized cases has decreased since October 2014. This trend is more pronounced from July 2015 onward, when all NPS street shops were closed.

By decisive nationwide and comprehensive promotion of anti-NPS measures, the number of NPS street shops that were once seen in many corners of the country rapidly decreased from 2014, and finally came to zero. As shown in Figure 9, there were 207 street shops identified in August 2014, but the number went down to zero by July 2015. This is because the police; the Ministry of Health, Labour and Welfare; and other related agencies have jointly conducted on-site inspections of NPS shops for direction and warnings, as well as thoroughly cracking down on their illicit activities, based on the government's establishment of the emergency countermeasure in July 2014, with the request of public opinion to tighten control. These efforts quickly reduced the number of street shops, and as described above, eliminated them by July 2015.

However, elimination of NPS street shops does not mean complete extinction of NPS abuse in Japan. With any crime, it is necessary not to make 


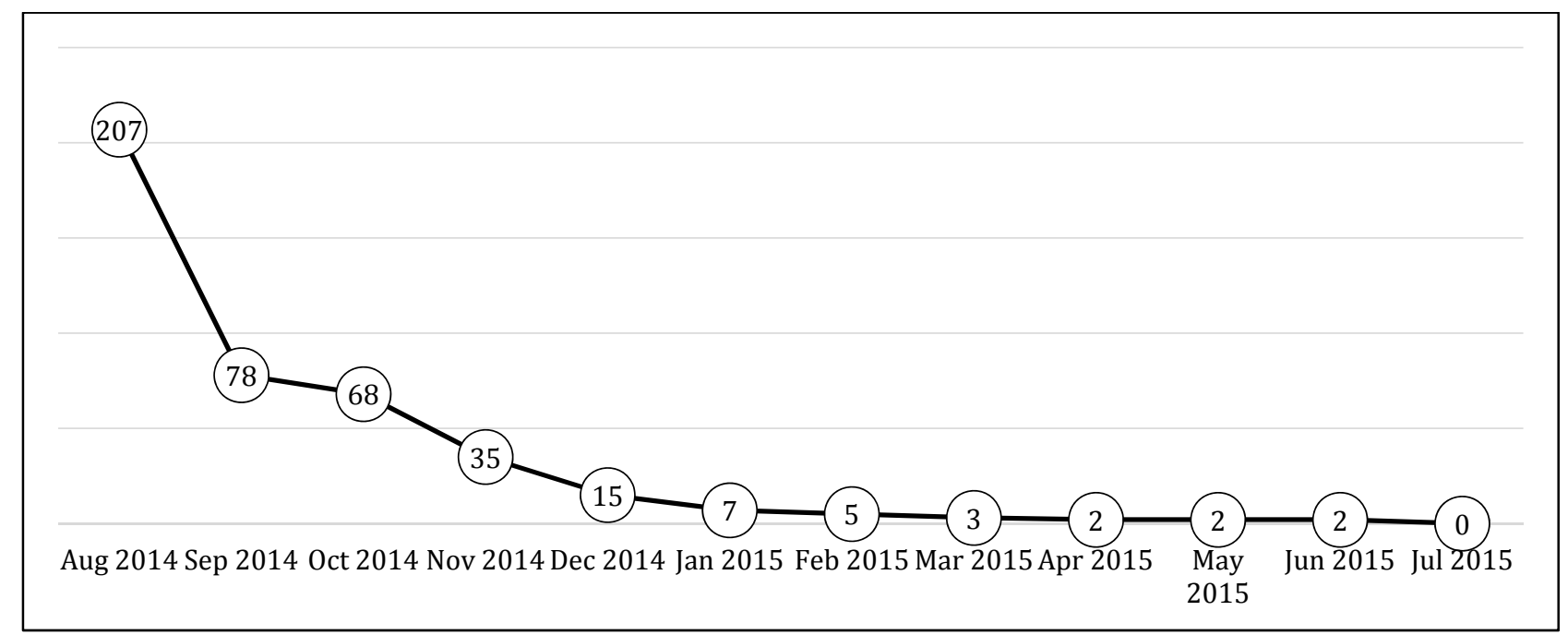

Figure 9. Progression of the Number of Shops.

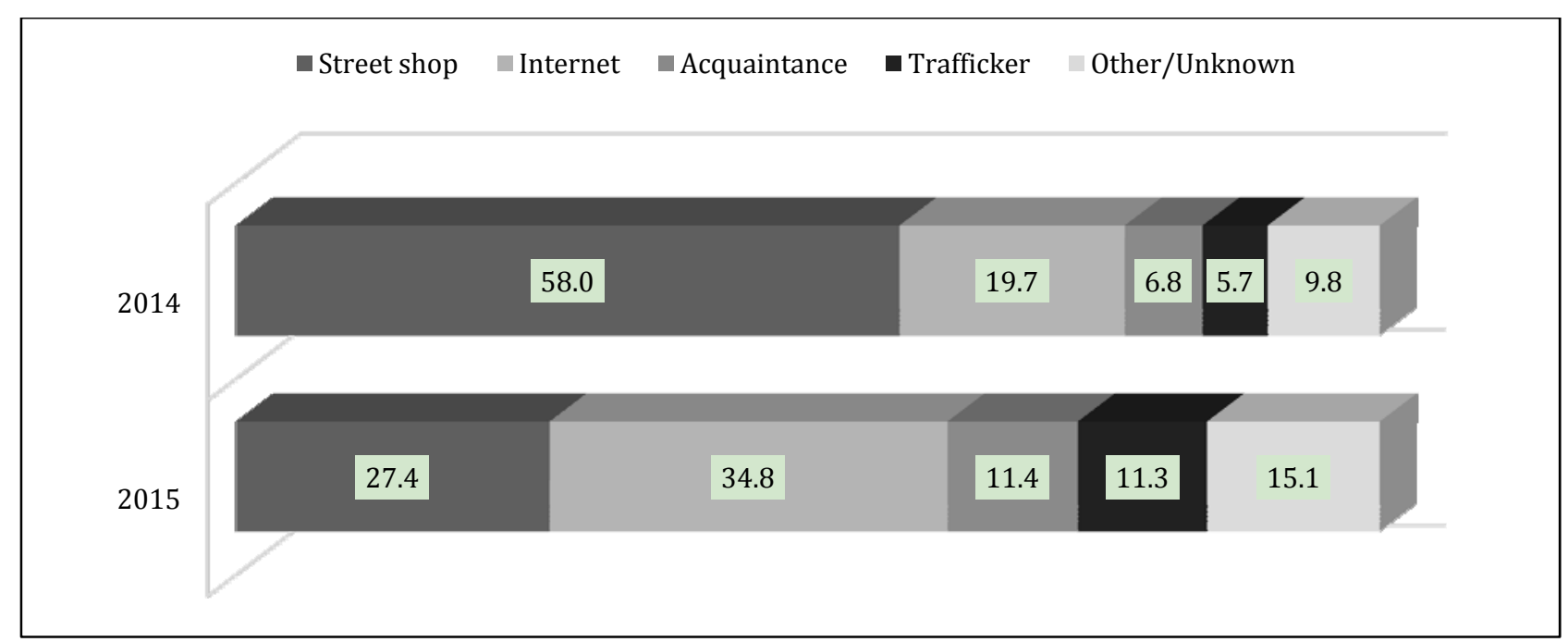

Figure 10. NPS: Means of Acquisition.

judgements only based on superficial phenomena, but to implement necessary measures based on activities that are conducted in cyberspace, underground worlds, and so on. The same applies to NPS, and as shown in Figure 10, as NPS street shops quickly ceased to exist, the means of acquisition of NPS has shifted to the Internet. In 2014, fully 58\% of NPS abusers obtained NPS from street shops, but in 2015, while the same rate was reduced to $27.4 \%$, those who obtained it through the Internet accounted for $34.8 \%$, an increase from $19.7 \%$ in 2014. To address this situation, the police have strengthened measures that include enhancement of cyber patrols.

\section{CONCLUSIONS}

So far, the author has described the overall drug situation in Japan. In conclusion, to outline the situation of drug abuse in Japan including future challenges, the author would like to highlight the following five points. 
First, as a result of the government-led implementation of comprehensive measures against drug abuse up to today, based on the Five-Year Drug Abuse Prevention Strategy, in response to public opinion, the situation of drug abuse in Japan has become less serious compared to the past and to the situation in many other countries. It is incorrect to understand that Japan has achieved a relatively favorable situation regarding drug abuse by simply depending on harsh penalties. Most first offenders arrested for use of stimulants, which accounts for $80 \%$ of drug abuse in Japan, are placed under probation and are not imprisoned at first offense ${ }^{2}$.

Moreover, as in many other countries, simple use of cannabis is not subject to penalties in $\mathrm{Japan}^{3}$. Especially those who repeat drug abuse are not in condition to control the use of drugs by their own will, and it is obvious that you cannot expect that imposing harsh penalties on them will bring about sufficient effects on drug abuse prevention.

After all, to prevent drug abuse, it is important to implement comprehensive and nationwide measures that include proactive provision of information to citizens on the situation of drug abuse, communication for awareness-raising, conducting drug abuse prevention class at schools, control by the police, and provision of counseling and treatment for drug abusers.

Second, due to progressing globalization of drug-related crime, a single country cannot alone accomplish measures against drug abuse, and the importance of international collaboration has become greater than ever. For example, of 73 arrests that the Japanese police made for smuggling stimulants in 2015, the countries of origin that accounted for the arrests, from the top, were China (21 cases or $28.8 \%$ of the total), Thailand (13 cases or 17.8\%), Hong Kong (eight cases or 11.0\%), and Mexico (six cases or $8.2 \%)$. The origins were not only nearby countries. Stimulants were also carried into Japan from countries that are geographically distant.
Meanwhile, on the premise that drug-related crimes are victimless crimes, one can argue that measures against drug abuse should focus basically on improvement of the situation through means other than control activities, such as treatment and counseling. However, looking at the reality surrounding drug abuse, and considering that drug abuse affects not only drug abusers themselves, but also those who are with them, such as families and spouses, in a serious manner, and consequently productive activities of the whole society, the author does not agree with the view that drug abuse is a victimless crime. Furthermore, since many drug abusers cannot control their use of drugs by their own will, and are not in a reasonable state to hold a job, there are even risks that they will commit other crimes to obtain money for illicit drugs, which have substantial or high prices. As Wada (2014) pointed out, relying solely on control activities not as a proper approach but rather as a method to place those who cannot control themselves temporarily in environments where they cannot use drugs, for the purpose of subsequent recovery, can be regarded as one effective approach among the overall measures against drug abuse.

Third, to add another choice for criminal control against drug abusers, and to enhance support for their rehabilitation in society, partial suspension of execution of sentences was newly introduced in June 2016. It is expected that this system will be used adequately in future to prevent drug abusers from relapsing into drug abuse. In Japan, the number of hospitals and organizations that provide treatment and counseling to drug abusers is not necessarily sufficient today, and improvement is needed on the receiving side of illicit drug in society by further strengthening collaboration among relevant government offices, hospitals, and related organizations.

Fourth, as mentioned earlier, the situation of drug abuse in Japan is less serious compared to the past and to the situation in many other countries. However, 
many arrestees are repeat offenders. When we look at offenders arrested in relation to stimulants, for example, out of 11,022 persons arrested in 2015, repeat offenders accounted for 7,147 (64.8\%). As Oshikiri and Akagi (2015) pointed out, to improve the overall situation concerning drug abuse, it is an important challenge to find ways to rehabilitate repeat offenders from drug abuse. In this regard, we need to enhance measures further to prevent repeat offences through application of partial suspension of execution of sentences, treatment not only in prisons but also in society, and further development of counseling systems.

Fifth, the situation regarding NPS is rapidly improving due to government-wide and comprehensive measures taken by relevant ministries and agencies. However, as komori (2015) pointed out, countermeasures against NPS have to be kept. While street shops have ceased to exist, the means of acquisition of NPS is quickly shifting to the Internet. Thus, from the viewpoint of blocking supply of the substances, it is necessary to strengthen cyber patrol more in future.

As true with any anti-crime measure, not only those against drug offences, however effective the measures may be, measures are not permanently effective. In accordance with changes in criminal methods and situations, we must constantly review the measures. Furthermore, not limiting measures to criminal investigations and trials, including various types of control, it is important to implement measures comprehensively, such as the wide provision of information to citizens as well as support to offenders and their families, educational efforts at schools, and administrative approaches by relevant ministries and agencies.

The author would be happy if this paper could contribute to establishing more effective measures, or promoting research, by related institutions and researchers who are concerned with measures against drug abuse.

\section{Notes}

1. From K. Wada, "Recent Trend of Drug Abuse and Dependence and Actual Situation and Issues of Treatment in Japan." The Journal of Police Science 67(12):111, published by Tachibana Shobo Company. The figures used in this document are from the National Survey on Drug Abuse in 2009 for Japan; the National Survey on Drug Use and Health (NSDUH), 2009, for the United States; the European Monitoring Center for Drug and Drug Addiction (EMCDDA), 2009, for the United Kingdom; the Canadian Addiction Survey (CAS), 2004, for Canada; and European Monitoring Center for Drug and Drug Addiction (EMCDDA), 2008, for Germany.

2. From the "White Paper on Crime 2007" by the Ministry of Justice, p. 237.

3. Simple use is not subject to penalties, but public opinion in Japan is that cannabis should be controlled as one of the controlled drugs. As a democratic nation, the ultimate decision as to which activities are subject to penalties are made by the Diet, which is the national legislative body, reflecting the opinions of the citizens. The police are engaged in various police activities that reflect public opinion, including crime investigations, drug abuse prevention class, and proactive disclosure of the situation for raising social awareness, to protect the lives, bodies, and property of the citizens, as well as to maintain public safety and order.

\section{References}

Aida, Y. 2015. “Special Guidance (Guidance on Withdrawal From Drug Dependency) Provided in the Kawagoe Juvenile Prison: Comprehensive Initiatives for Prevention of Repeated Crimes." Houritsu no Hiroba, August 2015. Pp. 20-28.

Higashiyama, T. 2013. "The Act to Amend the Penal Code, etc., and the Act Concerning Partial Suspension of Execution of Sentence for Persons Abusing Drugs, etc.” The Journal of Police Science 66(9):27-51.

Komori, S. 2015. "Actual Situation and Issues of Drug-Related Crimes: What NPS Left.” Houritsu no Hiroba, August 2015. Pp. 44-53.

National Police Agency. 2003. "2003 Police White Paper.”

_. 2015. "2015 Police White Paper.”

_ 2016. "Situation of Illicit Drugs and Firearms in 2015."

Oshikiri, H. and H. Akagi. 2015. "Overview of the Measures for Persons Arrested for Illicit Drugs in Rehabilitation.” Houritsu no Hiroba, August 2015. Pp. 29-36. 
Research and Training Institute of the Ministry of Justice. 2007. “2007 White Paper on Crime."

. 2015. "2015 White Paper on Crime.”

Wada, K. 2014. "Recent Trend of Drug Abuse and Dependence and Actual Situation and Issues of Treatment in Japan.” The Journal of Police Science 67(12):90-112.

Website of the Ministry of Health, Labour and Welfare. 2015. "Transition of the Number of NPS Shops."

\section{Bio}

Shinji Nakamura, B.A., chief professor of the National Police Academy in Japan (assistant commissioner), senior lecturer of Law School of Chuo University, Tokyo, Japan; research fields: strategies to keep social safety, countermeasures against organized crime, international investigative cooperation, policing. 